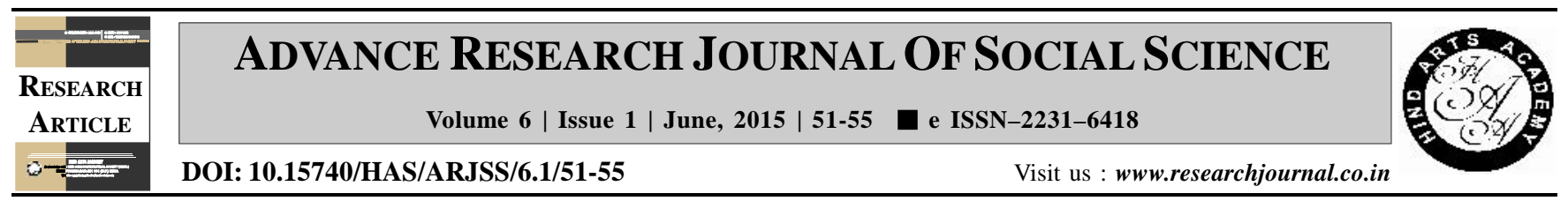

\title{
Impact of bee keeping training on socio-economic status of rural women
}

\author{
Anuradha Ranjan Kumari* and Laxmikant ${ }^{1}$ \\ Krishi Vigyan Kendra (I.I.V.R.), MALHANA DEORIA (U.P.) INDIA \\ (Email: anuradha_rau@ rediffmail.com) \\ ${ }^{1}$ Krishi Vigyan Kendra (S.V.P.U.A.\&T.), RAMPUR (U.P.) INDIA
}

\section{ARTICLE INFO :

$\begin{array}{lll}\text { Received } & : & 29.01 .2015 \\ \text { Revised } & : & 21.04 .2015 \\ \text { Accepted } & : & 04.05 .2015\end{array}$

KEY WORDS :

Bee keeping, Socio-economic status, Trained, Untrained

HOW TO CITE THIS ARTICLE :

Kumari, Anuradha Ranjan and Laxmikant (2015). Impact of bee keeping training on socio-economic status of rural women. Adv. Res. J. Soc. Sci., 6 (1): 51-55.

*Author for correspondence

\section{ABSTRACT}

Bee keeping is an ideal activity for the socio-economic development of rural people. It does not require any sophisticated equipments and the technology employed is simple and within easy grasp of illiterate rural people. The study was conducted in Pusa block of Samastipur district selected purposively. A list of women trainees, who have obtained from Apiculture Research Training Centre, Pusa. From these lists 50 trained women were randomly selected who have attained seven days duration of training programme. Equal no of untrained women beekeepers, who have not undergone any skill oriented training, were also selected randomly, to serve as control group. Hence, trained from seven village selected for this study. The majority of trained as well as untrained women belonged to middle age group as (31-50years). Bee keeping was adopted by most of the backboard cost it was not influenced caste system of the society. Most of the trained women were belonged to high category of education while untrained women, maximum 50.00 per cent of respondents belonged to low level of education. Maximum percentage of trained as well as untrained respondents were enjoyed in laborer followed by farming, business and service, respectively bee keeping was adopted by most of the small family size. Most of the rural women preferred nuclear family and also it is in product. The maximum respondents do not possess any land in both groups hence they have opted divested to words bee keeping occupation for this livelihood. The percentages of women in for categories were more or less same in two groups i.e., trained and untrained. Maximum respondents had lived in pucca house and enjoy with traditional materials like radio, chair, cycle, watch indicating medium level of economic in study village. Both of groups one almost similar with respect to social participation. Bee keeping training might have somehow or the other helped in developing compel, tines among the trained group. As for as economic motivation trained as well as untrained women maximum percentage fell under the medium economic motivation category. 